\title{
Mucocutaneous candidiasis: the IL-17 pathway and implications for targeted immunotherapy
}

\author{
Anna R Huppler', Shrinivas Bishu² and Sarah L Gaffen ${ }^{3,4, *}$
}

\begin{abstract}
IL-17 and related cytokines are direct and indirect targets of selective immunosuppressive agents for the treatment of autoimmune diseases and other diseases of pathologic inflammation. Insights into the potential adverse effects of IL-17 blockade can be drawn from the experience of patients with deficiencies in the IL-17 pathway. A unifying theme of susceptibility to mucocutaneous candidiasis is seen in both mice and humans with a variety of genetic defects that converge on this pathway. Mucocutaneous candidiasis is a superficial infection of mucosal, nail or skin surfaces usually caused by the fungal pathogen Candida albicans. The morbidity of the disease includes significant pain, weight loss and secondary complications, including carcinoma and aneurysms. This review describes the known human diseases associated with chronic mucocutaneous candidiasis (CMC) as well as the known and proposed connections to IL-17 signaling. The human diseases include defects in IL-17 signaling due to autoantibodies (AIRE deficiency), receptor mutations (IL-17 receptor mutations) or mutations in the cytokine genes (IL17F and IL17A). Hyper-lgE syndrome is characterized by elevated serum IgE, dermatitis and recurrent infections, including CMC due to impaired generation of IL-17-producing Th17 cells. Mutations in STAT1, IL12B and IL12RB1 result in CMC secondary to decreased IL-17 production through different mechanisms. Dectin-1 defects and CARD9 defects result in susceptibility to C. albicans because of impaired host recognition of the pathogen and subsequent impaired generation of IL-17producing T cells. Thus, recent discoveries of genetic predisposition to $\mathrm{CMC}$ have driven the recognition of the role of IL-17 in protection from mucosal fungal infection and should guide counseling and management of patients treated with pharmacologic IL-17 blockade.
\end{abstract}

\section{Introduction}

Considerable attention and research dollars have focused on the cytokine interleukin-17 (IL-17 or IL-17A) and the pathology associated with aberrant IL-17 signaling. In many cases, an excess of IL-17 is associated with abnormal inflammation, implicated in rheumatoid arthritis, asthma, psoriatic arthritis, ankylosing spondylitis, systemic lupus erythematosus and autoimmune encephalomyelopathy (reviewed in [1]). Not surprisingly, IL-17 and related cytokines have become a prime target for pharmaceutical management of these diseases (reviewed in [2]). Targeted biologics are an appealing method to combat pathologic inflammation while avoiding non-specific immunosuppression. There are currently Food and Drug Administration-approved monoclonal antibodies for the treatment of rheumatologic and autoimmune diseases

*Correspondence: sig65@pitt.edu

${ }^{4}$ BST S703, 3500 Terrace St, Division of Rheumatology and Clinical Immunology,

Pittsburgh, PA 15261, USA

Full list of author information is available at the end of the article targeting various cytokines and immune factors, including TNF- $\alpha$, IL-1, cytotoxic T-lymphocyte-associated antigen 4 (CTLA-4), B cells (CD20), IL-6, IL-12/23p40, and so on. Although not originally designed with that intent, many if not all of these drugs target the IL-17 pathway. Drugs are currently in development that target the T-helper cell 17 (Th17) pathway, including IL-17 and its receptor, IL-23p19 and IL-22, among others [3-9]. Rigorous clinical trials and post-marketing studies are essential to reveal possible unexpected consequences of targeted immune blockade. In addition, attention to 'experiments of nature' in which mutations lead to alterations in cytokine pathways are a useful adjunct to predict adverse effects of the new biologic agents. This review will focus on the IL-17/Th17 pathway and mucocutaneous candidiasis, an opportunistic infection associated with immunodeficiency, with reference to the known or potential impact of cytokine blockade.

IL-17 is secreted by the Th17 subset of CD4+ lymphocytes, as well as CD8 T cells and innate cells, including natural killer $\mathrm{T}$ cells, lymphoid tissue inducer cells, innate lymphoid cells and $\gamma \delta$-T cells [10]. Th17 cells are highly 


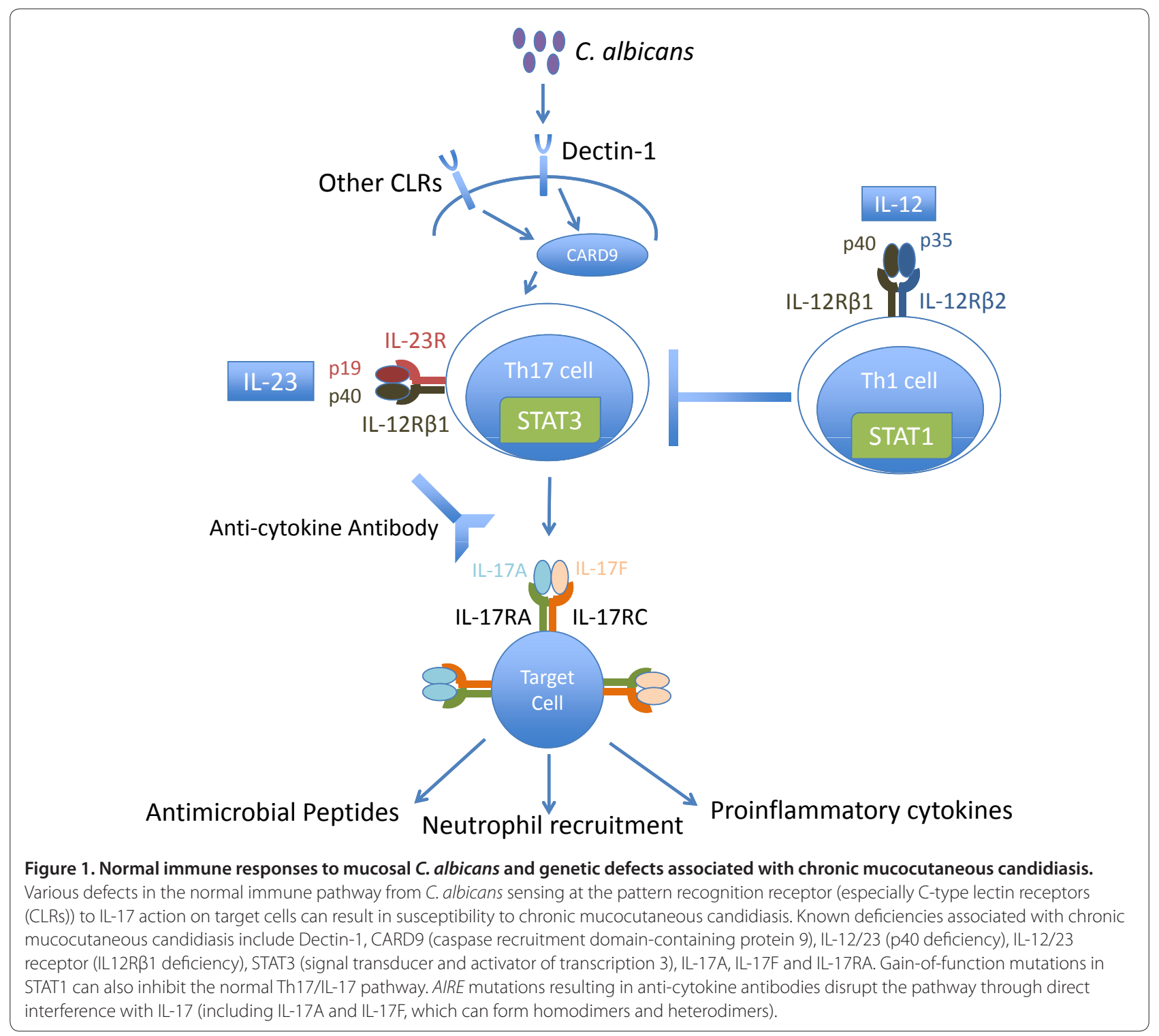

protective against extracellular pathogens and can participate in immunity to intracellular bacteria and perhaps certain viruses, especially at mucosal surfaces (reviewed in [11]). A notable extracellular pathogen at the oral mucosa is C. albicans, a commensal yeast that frequently colonizes the mouth, colon or vagina in healthy individuals [12]. Asymptomatic colonization generally only progresses to disease in the face of an additional risk factor, such as immunosuppression, disruption of normal barriers, surgery or broad spectrum antibiotics [13-15]. We recently demonstrated in mice that the IL-23/IL-17 axis of immunity is critical for immunity to Candida in the oropharynx using mice lacking IL-23 or either IL-17 receptor subunit (IL-17RA and IL-17RC) [16,17]. Similarly, immunity to dermal and disseminated candidiasis in mice is regulated by the IL-17 pathway $[18,19]$. In humans, the majority of Candida-specific memory T cells express IL-17 and CCR6 (a Th17 marker) [20], clearly linking the IL-17 pathway to antifungal immunity (Figure 1).

Candida infections of the mucosal, nail or skin surfaces are termed mucocutaneous candidiasis. In patients with an underlying genetic or immune defect leading to susceptibility to these infections, the disease is often persistent and chronic, termed chronic mucocutaneous candidiasis (CMC). The direct manifestations of CMC are Candida plaques (usually C. albicans) on the oral, esophageal or genital mucosa or thickened skin and nails (reviewed in [21]). Susceptible individuals may also experience recurrent infections with dermatophytes. Although symptoms can be benign, they often cause significant morbidity due to pain, weight loss or failure to 
thrive, or more severe secondary complications such as squamous cell carcinoma, debilitating hands, esophageal stricture or cerebral aneurysms [22-25]. Interestingly, mucocutaneous candidiasis is rarely associated with disseminated candidal disease [26]. In the past few years, multiple genetic etiologies causing this disease have been described. Strikingly, most relate directly or indirectly to defects in IL-17, supporting the notion that not only is the IL-17 pathway critical for regulating anti-fungal immunity, but defects in IL-17 predispose primarily to infection with $C$. albicans and surprisingly few other microbes.

\section{Defects in the IL-17 pathway AIRE deficiency}

Autoimmune polyendocrinopathy syndrome-I (APS-I), also known as autoimmune polyendocrinopathy candidiasis ectodermal dystrophy (APECED), is an autosomal recessive disorder caused by mutations in the autoimmune regulator (AIRE) gene. Mutations in AIRE lead to aberrant thymic self-tolerance mechanisms and loss of thymic deletion of autoreactive $\mathrm{T}$ cells. The classic triad of this disease is CMC, typically presenting by age 6 , hypoparathyroidism and adrenocortical failure [27,28]. The prevalence of the disease varies worldwide, but is highest in Iranian Jews (about 1:9,000), Sardinians $(1: 14,000)$, and Finnish populations $(1: 25,000)$, with men and women equally affected (reviewed in [25]). A widerange of disease manifestations has been described, including, in descending order of prevalence, dental enamel dysplasia, nail dystrophy, alopecia, ovarian failure, vitiligo, diabetes mellitus, testicular failure and hypothyroidism. CMC is nearly universal in APS-I patients $[27,29]$, but they are not prone to other infections. The lone infectious susceptibility associated with this disease was initially mysterious, but now is tied to neutralizing autoantibodies against cytokines detected in these patients [30]. The most common anti-cytokine autoantibodies are directed against the type I interferons (IFNs) and Th17-related cytokines, notably IFN- $\omega$ (100\% of patients), IFN- $\alpha$ (95\%), IL-22 (91\%), IL-17F (75\%), and IL-17A (41\%) [27]. Similar high prevalence of antibodies against IL-17A, IL-17F and IL-22 has been found in APS-1 in other studies [31]. Plasma from patients with autoantibodies against IL-17 abolishes IL-17 responsiveness (measured by IL-6 production) in fibroblasts, confirming that these antibodies interfere with IL-17 activity [31].

Although APS-1 is not the only human disease resulting from abnormal autoantibodies, it is the only such disease associated strongly with CMC. This is most likely due to the unique spectrum of anti-cytokine autoantibodies produced as a result of AIRE deficiency. For example, a different pattern of anti-cytokine autoantibodies is found in patients with thymoma. Thymoma patients have a high prevalence of antibodies to IFN- $\omega$, IFN $\alpha$ and IL-12, but a low prevalence of antibodies to IL-22, IL-17F or IL-17A [27]. CMC is an unusual manifestation of thymoma, but its occurrence correlates with the presence of autoantibodies against both IL-17A and IL-22 [30], further supporting the concept that neutralizing Th17-specific cytokines increases susceptibility to candidiasis. Thus, the pathogenesis of APECED with respect to $\mathrm{CMC}$ seems to be tightly linked to neutralizing Th17 cytokines, suggesting that IL-17 neutralization applied in other settings increases the risk for CMC.

\section{IL-17 receptor mutations}

The most direct evidence for a role in the IL-17 pathway in host resistance to $\mathrm{CMC}$ comes from a recent report of a case of homozygous mutation in the IL-17A receptor $(I L 17 R A)$. The mutation was found in a French child of Moroccan descent with autosomal recessive CMC [32]. The child presented with Candida dermatitis starting in the neonatal period and Staphylococcus aureus dermatitis at 5 months of age. Sequencing of multiple genes related to IL-22 or IL-17 signaling (IL22, IL22RA1, IL10RB, $I L 17 A, I L 17 F, I L 17 R A, I L 17 R C)$ revealed a homozygous nonsense mutation in the IL17RA gene (c.850C $>\mathrm{T}$ / c. $850 \mathrm{C}>\mathrm{T}$ ), which results in a premature stop codon in the extracellular domain of the receptor. The child's parents and siblings were heterozygous for the allele and asymptomatic. A database of healthy controls from 52 ethnic groups, as well as French and Moroccan controls, failed to reveal any other cases of this mutation. The patient's blood and tissue were studied in more detail, which revealed a lack of IL-17RA protein on the surface of fibroblasts and peripheral blood mononuclear cells. IL-17RC, IL-22RA1, IL-17A and IL-22 expression levels were normal. The patient's fibroblasts did not respond to IL-17A or IL-17F in terms of producing prototypical IL-17 target proteins such as IL-6 or growth-regulated oncogene- $\alpha$ (GRO $\alpha$, also known as CXCL1 or KC in mice). Importantly, normal function was restored upon transfection of fibroblasts with wild-type $I L 17 R A$, verifying that this manifestation was not from another undetected mutation. The phenotype of homozygous IL17RA mutation in humans is consistent with findings that IL-17RA- and IL-17RC-deficient mice are more susceptible to oropharyngeal candidiasis, and suggests that data from mouse models are a good predictor of human susceptibility to candidiasis $[16,17]$.

\section{IL-17A deficiency}

A kindred with autosomal dominant $\mathrm{CMC}$ who lack the IL-17 family member IL-17A and Th17 cells has been described [28]. The exact defect is unknown but it appears to be posttranscriptional since $I L-17$ mRNA 
levels were preserved [28]. Additional patients with CMC have been described with decreased production of IL-17A and IL-22 of unknown underlying etiology [33]. The emerging evidence of a role for IL-17A in human susceptibility to Candida is supported by work in mice. For example, IL-17A-deficient mice have impaired clearance of C. albicans infection from the skin [19].

The role of IL-22 is less clear, as IL22-/- mice are not susceptible to either dermal or oral candidiasis [17,19]. In a gastric model of candidiasis in mice, IL-22 does appear to be protective [34], perhaps due to its well known role in promoting epithelial repair in the mucosa [35]. More work is needed to determine its precise contribution to antifungal immunity.

\section{IL17F mutation}

A form of autosomal dominant CMC with incomplete penetrance results from mutation in the IL-17 family member IL17F [32]. This mutation was first described in four members of a family from Argentina with autosomal dominant inheritance of CMC. A thorough analysis of genes related to IL-17 signaling revealed a heterozygous missense mutation in the $I L 17 F$ gene of the index case. The mutation (c.284C $>\mathrm{T}$ ) resulted in the replacement of a conserved serine with leucine. This mutation was not found in the control patient database. Based on computational analysis, the missense mutation is predicted to interfere with cytokine to receptor binding. All tested members of the kindred with CMC were heterozygous for this mutation. Two apparently healthy family members also had the allele, suggesting incomplete penetrance. By flow cytometry, IL-17F-expressing T cells were absent in affected family members. In vitro studies of the mutant protein revealed defective binding to IL-17RA on fibroblasts, with weaker IL-6 and GRO- $\alpha$ induction. Peripheral blood mononuclear cells also had impaired induction of cytokines when stimulated with the mutant protein.

This finding was somewhat surprising, as IL-17F is not a strong agonist of the IL-17 receptor compared to IL-17A, and $I L 17 F-/$ - mice were not highly susceptible to disseminated candidiasis [36]. However, IL-17A and IL-17F form both homodimers and heterodimers [37], and the mutant IL-17F identified in this patient cohort blocks signaling from the IL-17A:F form of the cytokine [32]. Thus, blockade of either IL-17A or IL-17F may predispose to mucosal candidiasis.

\section{Hyper-IgE syndrome}

The hyper-IgE syndromes (HIESs, Job's syndrome) comprise a group of primary immunodeficiencies characterized by elevated serum IgE, dermatitis and recurrent infections primarily of the skin and lungs. The infectious predilections in autosomal-dominant HIES include CMC and bacterial infections with S. aureus, Streptococcus pneumonaie and Haemophilus influenzae. Most cases of HIES are sporadic, resulting from a dominant negative mutation in the signal transducer and activator of transcription 3 (STAT3) [38,39]. The mutations are primarily in the DNA-binding domain or Src homology 2 (SH2) domain of STAT3 and lead to the impaired generation of Th17 cells [40]. Since STAT3 is downstream of IL-22, cellular responses to this Th17-derived cytokine are also impaired. In fact, IL-17 production by $\mathrm{T}$ cells is absent in cells from HIES individuals after stimulation with Staphylococcus enterotoxin B or C. albicans [41]. The mutations in STAT3 result in decreased expression of regulator retinoid-related orphan receptor $\gamma \mathrm{t}$ (ROR $\gamma \mathrm{t}$ ), a transcription factor required for IL-17 expression, and decreased differentiation into Th17 cells by naïve CD4+ $\mathrm{T}$ cells [42]. The specific infectious susceptibility of HIES patients to skin and pulmonary infections appears do be due to a site-specific requirement of Th17 cytokines to produce antimicrobial factors, found both in skin and salivary gland tissue $[43,44]$.

Autosomal recessive HIES is a related, but distinct disorder. Most patients affected by this disease are deficient in dedicator of cytokinesis 8 (DOCK8), leading to impaired T-cell activation and maintenance of memory. As in autosomal-dominant HIES, these patients have elevated IgE levels, eczema, recurrent bacterial infections and CMC $[45,46]$. The unique disease manifestations include susceptibility to recurrent viral infections (most commonly herpes viruses, molluscum contagiosum virus and human papillomaviruses), asthma, severe food allergies, malignancy at young age and unusual autoimmune diseases. Some DOCK8-deficient patients have decreased numbers of Th17 cells (reviewed in [47]). One additional case of autosomal recessive HIES associated with a tyrosine kinase 2 (Tyk2) deficiency has been described [48]; however, a case of Tyk2 deficiency resulting in a phenotype without eczema, candidiasis or hyper-IgE has also been reported [49]. Tyk2 is a member of the Janus kinase (JAK) family that signals downstream of IL-23 and hence is needed for efficient Th17 maintenance in vivo. Accordingly, HIES can be caused by various genetic lesions, but the common thread appears to be regulation of the IL-17/Th17 pathway.

\section{STAT1 mutation}

Using a genome-wide approach based on whole-exome sequencing, gain-of-function STAT1 mutations were recently associated with isolated CMC [50]. Twelve missense mutations were found in 47 patients from 20 kindreds of CMC without other clinical features. These mutations were in the coiled-coil domain of STAT1, in a pocket near residues essential for STAT1 dephosphorylation. Mutations at this site result in 
gain-of-function STAT1 phosphorylation leading to enhanced transcription of STAT-1-dependent genes in response to various cytokines. The STAT1 mutant products enhance cellular response to cytokines IFN $\alpha / \beta$, IFN $\gamma$ and IL-27, which are all known inhibitors of the Th17 pathway. These patients had disease involving a range of cutaneous and mucosal sites, including nails, oral cavity, oropharynx, genital mucosa, skin and esophagus. Some patients had thyroid autoimmunity (8 of 47) and one had systemic lupus erythematosus. Squamous cell carcinoma was the cause of death in four patients, and cerebral aneurysm in two.

STAT1 mutations were also demonstrated in 14 autosomal dominant cases of CMC from five families [51]. In addition to $\mathrm{CMC}$, members of one family suffered from various autoimmune diseases (autoimmune hepatitis, autoimmune hemolysis, pernicious anemia and antiphospholipid antibodies) as well as symptomatic cytomegalovirus infection and Pneumocystis carinii pneumonia. Three families suffered from hypothyroidism while the fifth family did not have associated autoimmune disease. Three families had histories of oral squamous-cell carcinoma or esophageal cancer. Analysis revealed heterozygous mutations in STAT1 in only the affected family members. These mutations were located in the coiled-coil domain of STAT1, and led to defective Th1 and Th17 responses with reduced production of INF- $\gamma$, IL-17 and IL-22 in response to Candida stimulation [50]. Therefore, STAT1 gain-of-function mutations result in CMC through a similar final pathway as other IL-17 signaling defects.

\section{IL-12R $\beta 1$ or IL-12p40 deficiency}

Patients with inborn errors of the IL-12/IL-23 or IFNY signaling axis, also known as Mendelian susceptibility to mycobacterial diseases (MSMD), are susceptible to mycobacteria. Infectious susceptibility includes weakly virulent species of mycobacteria such as the bacillus Calmette-Guérin (BCG) vaccine and severe disease caused by Salmonella serotypes [52]. A recent review of 132 patients with the most common form of this disease, IL-12R $\beta 1$ deficiency, found that $24 \%$ have mucocutaneous disease caused by Candida albicans, usually manifesting as recurrent oral thrush [53]. The two mutated genes associated with MSMD are $I L 12 B$ and IL12RB1. Patients with $I L 12 B$ null mutations lack the IL-12p40 subunit, a shared component of both IL-12 and IL-23 [54]. Similarly, the IL12RB1 gene encodes the shared chain of the IL-12 and IL-23 receptors (Figure 1). The susceptibility to mycobacterial disease is almost certainly rooted in the deficiency in IL-12 signaling and Th1 cells, which are central to clearance of intracellular pathogens. In contrast, defective IL-23 signaling impairs the expansion and maintenance of Th17 cells and IL-17 signaling.
Patients with mutations in IL12RB1 and IL12B have low proportions of IL-17A-producing $\mathrm{T}$ cells in circulation, which likely explains the susceptibility to CMC [40].

\section{C-type lectin receptor pathway defects Dectin-1 defects}

Dectin-1 is a fungal pattern recognition receptor (PRR) that recognizes $\beta$-glucans, carbohydrates located in the cell wall of the yeast form of Candida (Figure 1). C-type lectin receptors (CLRs) such as Dectin-1 are emerging as important mediators of innate anti-fungal immunity, although there are still many unanswered questions about their specific roles in vivo [55]. Studies of Dectin-1 knockout mice revealed increased susceptibility to gastrointestinal colonization with C. albicans and varying susceptibility to disseminated candidiasis, depending on the strain of Candida used (reviewed in [56]). In humans, the Dectin-1 polymorphism Y238X leads to a premature stop codon and increased susceptibility to CMC in three described homozygous patients [57]. CMC in these patients was characterized by vulvovaginal candidiasis or onychomycosis with Trichophyton rubrum. Monocytes and macrophages in these patients had lower fungalsensing capacity, with decreased production of IL- 6 after stimulation with $\beta$-glucan, heat-killed $C$. albicans or live C. albicans. Consequently, impaired Th17 generation resulted in reduced IL-17 production. Compared to other genetic lesions that promote $\mathrm{CMC}$, however, disease was mild in these patients, suggesting that their susceptibility may be multifactorial. Furthermore, while family members heterozygous for the polymorphism exhibited an intermediate reduction in proinflammatory cytokines, there was only mild transient candidal disease in one person. Follow-up studies revealed that this polymorphism was found on a population-wide search in individuals from Europe and Africa and is associated with increased Candida colonization in immunosuppressed hematopoietic stem cell transplant recipients [57,58]. Therefore, Dectin-1 appears to contribute to immune recognition of Candida and presents a link between pathogen sensing and IL-17 production.

\section{CARD9 defects}

Caspase recruitment domain-containing protein 9 (CARD9) is a signal transducer downstream of many fungal PRRs, including most of the CLRs. Mice deficient in CARD9 exhibit severely reduced TNF- $\alpha$ and IL-2 production in response to zymosan, a yeast cell wall component principally composed of $\beta$-glucans, but not other PRR ligands [59]. As discussed above, the primary receptor for $\beta$-glucans is Dectin-1, a CLR that transduces signals via spleen tyrosine kinase (Syk) activation and PKC ultimately activating the NF- $\mathrm{KB}$ and mitogen-activated protein kinase (MAPK) pathways [60-62]. CARD9-deficient 
mice have an impaired immune response to systemic challenge with $C$. albicans, with accelerated mortality and higher organ fungal burdens compared to heterozygous littermates [59]. CARD9 defects in humans were first reported in a large consanguineous Iranian family with CMC and peripheral dermatophytosis [63]. CARD9 deficiency results from a homozygous point mutation, Q295X, on chromosome 9q leading to a premature stop codon and loss-of-function. The mutation was not found in healthy family members or 230 healthy unrelated controls. Patients with this defect have low proportions of IL-17A-producing $\mathrm{T}$ cells and an almost complete defect in the generation of a Th17 response. The phenotype in CARD9-deficient patients is distinct from that of other genetic causes of CMC in that it also includes susceptibility to invasive candidiasis. Three of eight affected family members died of central nervous system candidiasis. The fact that the phenotype seems to be so severe compared to the Dectin-1-deficient cohort suggests that other CARD9-utilizing CLRs, such as Dectin-2 and/or Mincle, are equally or more important for anti-Candida immunity.

\section{Other causes of chronic mucocutaneous candidiasis}

There are additional causes of human CMC with defects in known pathways, many of which can be readily linked to Th17. Inborn errors of NF- $\mathrm{KB}$ activation, known as IкB $\alpha$ deficiency, can cause this disease. IL-17 activates NF- $\kappa B$ directly $[64,65]$, as do the CLRs that bind fungal cell wall components and promote Th17 development. Deficiency in NF- $\mathrm{kB}$ activity leads to severe impairment in T-cell receptor signaling and susceptibility to CMC [65]. Consistently, non-specific inherited defects in T-cell immunity, including DiGeorge syndrome and severe combined immunodeficiency (SCID), are associated with susceptibility to CMC [14]. HIV/AIDS patients are extremely susceptible to oral candidiasis, which is linked to reduced CD4+ T-cell counts. Recent data indicate that Th17 cells are lost preferentially during HIV infection, perhaps explaining the specific array of opportunistic infections associated with AIDS [66]. Non-specific immunosuppression secondary to cancer chemotherapy or immunosuppressive agents also increases susceptibility to CMC [15].

Some secondary conditions not directly related to $\mathrm{T}$ cells or IL-17 also predispose to $\mathrm{CMC}$, such as hyperglycemia or long-term use of broad-spectrum antibiotics $[67,68]$. Moreover, the salivary gland plays a critical role in oral mucosal immunity. CMC is prevalent in individuals with dentures, with salivary defects such as Sjögren's syndrome, following head or neck radiation therapy or with drugs causing xerostomia [67]. We recently showed that HIES patients have defective salivary killing activity towards C. albicans, associated with reduced levels of antimicrobial peptides such as defensins and salivary histatins [44]. Although IL-17 can signal directly on salivary gland acinar cells [44], these defects may also be independent of the IL-17 pathway.

\section{Biologic therapies and chronic mucocutaneous candidiasis}

The increased understanding of the Th17-IL17 axis in the pathogenesis of autoimmune conditions has given rise to new classes of biologics. In addition to currently available agents that broadly target inflammatory cytokines or T-cell activation, newer drugs with specificity for Th17 effector cytokines (IL-17, IL-21, IL-22) and inhibitors of signaling molecules important for Th17 cell activation are currently in early clinical trials [69]. The rise of these agents brings to the forefront the important question of susceptibility to CMC in patients receiving more targeted biologic therapies. Currently approved agents have thus far not been associated with susceptibility to CMC $[70,71]$. Cumulative data demonstrate that the primary susceptibilities are to Mycobacterium tuberculosis, (presumed) bacterial sino-pulmonary infections, Histoplasma capsulatum and JC virus (all associated with TNF $\alpha$-inhibitors) [72,73]. Surprisingly, IL-1 receptor antagonists, IL-6 receptor antagonists and CTLA4 agonists are not associated with increased infectious risk compared with placebo (although there is trend toward susceptibility) [71,74]. Additionally, antibodies against the shared IL-12/23p40 subunit are associated with a slightly increased risk for (presumed bacterial) sinopulmonary infections, but not for CMC [75-78]. Similarly, newer agents, which inhibit the JAKs and Syk, are associated with increased risk of (presumed bacterial) sino-pulmonary infections, but not CMC $[79,80]$. This is perhaps somewhat surprising, since the JAKs, STATs and Syk are all important for induction of Th17 cells downstream of multiple cytokines and/or PRRs. Although the cumulative clinical trial evidence suggests that biologics do not confer susceptibility to CMC, it is important to bear in mind that with their increased use, biologics may be found to increase susceptibility to CMC in patients with otherwise subclinical mucosal Candida colonization. This may especially be true when biologics are coupled with other predisposing factors (for example, corticosteroid use). The results of on-going large scale phase 4 studies may identify a subset of patients with a propensity to develop CMC that would benefit from prophylaxis with anti-fungal agents.

\section{Perspectives}

In the past several years, many causes of isolated CMC and $\mathrm{CMC}$ associated with other abnormalities have been elucidated. Combined with the recent work on IL-17 and 
Th17 cells in mice, this has led to an expanded understanding of the mechanism of host defense from C. albicans at mucosal surfaces and the role of IL-17 in immunity from infection. IL-17 is essential for normal resistance to Candida infection in the oral mucosa, vagina mucosa, skin and nails. The normal functioning of the immune defense requires intact PRRs, including Dectin-1, and signal transduction, including CARD9. Th17 cells are generated and maintained, which requires normal IL-23 signaling (that is, normal IL12B and IL12RB1 gene products). Signal transduction requires normal STAT1 (no gain-of-function) and normal STAT3 (no loss-of-function) activity. Finally, IL-17 and IL-17R are functional without the presence of blocking antibodies (Figure 1).

Use of biologic therapy to treat autoimmune diseases and diseases of abnormal inflammation has been on the rise. Some adverse effects of these medications are known based on vigorous clinical trials, but others can be extrapolated from an expanded understanding of the complex mechanisms of the immune system. In the case of therapy targeting the IL-17 pathway, increased susceptibility to CMC should be anticipated. Prompt recognition and treatment of symptoms of mucocutaneous candidiasis are likely to increase the tolerability and safety of these medications. Some patients with recurrent issues may further benefit from antifungal prophylaxis. Prophylaxis could likely be targeted at mucosal surfaces, since disseminated or invasive candidiasis is rarely seen in patients with isolated defects in IL-17 signaling or CD4 deficiency. However, increased risk of candidiasis, potentially even disseminated disease, may occur in patients on combination immunosuppressive therapy. For example, IL-17 blockade could increase the rate of asymptomatic colonization without signs of overt disease. With the addition of therapeutic agents targeting other segments of the immune system, asymptomatic colonization predisposes patients to invasive disease. Consequently, careful consideration of the cumulative risk for fungal infections is warranted.

This article is part of the series on Adult immunodeficiency, edited by Hans-Hartmut Peter. Other articles in this series can be found at http://arthritis-research.com/series/immunodeficiency

\section{Abbreviations}

APECED, autoimmune polyendocrinopathy candidiasis ectodermal dystrophy: APS, autoimmune polyendocrinopathy syndrome; CARD, caspase recruitment domain-containing protein; $C L R$, C-type lectin receptor; $C M C$, chronic mucocutaneous candidiasis; CTLA, cytotoxic T-lymphocyte-associated antigen; DOCK, deficient in dedicator of cytokinesis; GRO, growth-regulated oncogene; HIES, hyper-IgE syndrome; IFN, interferon; IL, interleukin; IL-17R, IL-17 receptor; JAK, Janus kinase; MSMD, Mendelian susceptibility to mycobacterial diseases; NF, nuclear factor; PRR, pattern recognition receptor; STAT, signal transducer and activator of transcription; Syk, spleen tyrosine kinase; Th, Thelper; TNF, tumor necrosis factor.

\section{Competing interests}

The authors declare that they have no competing interests.

\section{Acknowledgments}

SLG was supported by the NIH (AR054389, DE022550). SB was supported by $\mathrm{NIH}$ training grant T32 DK063922. ARH was supported in part by Children's Hospital of Pittsburgh of the UPMC Health System, and by a Pediatric Infectious Disease Society Award, funded by the Stanley A Plotkin Sanofi Pasteur Fellowship Award.

\section{Author details}

'Childrens Hospital of UPMC, Division of Pediatric Infectious Diseases, Pittsburgh, PA 15224, USA. ${ }^{2}$ University of Pittsburgh, Division of Gastroenterology, Hepatology and Nutrition, Pittsburgh, PA 15261, USA. ${ }^{3}$ University of Pittsburgh, Division of Rheumatology and Clinical Immunology, Pittsburgh, PA, USA. ${ }^{4}$ BST S703, 3500 Terrace St, Division of Rheumatology and Clinical Immunology, Pittsburgh, PA 15261, USA.

Published: 23 July 2012

\section{References}

1. Hu Y, Shen F, Crellin NK, Ouyang W: The IL-17 pathway as a major therapeutic target in autoimmune diseases. Ann N Y Acad Sci 2011 1217:60-76.

2. Strzepa A, Szczepanik M: IL-17-expressing cells as a potential therapeutic target for treatment of immunological disorders. Pharmacol Rep 2011, 63:30-44.

3. Curtis JR, Singh JA: Use of biologics in rheumatoid arthritis: current and emerging paradigms of care. Clin Ther 2011, 33:679-707.

4. Szekanecz Z, Szanto S, Szabo Z, Vancsa A, Szamosi S, Bodnar N, Szucs G: Biologics - beyond the joints. Autoimmun Rev 2010, 9:820-824.

5. La Cava A: Anticytokine therapies in systemic lupus erythematosus. Immunotherapy 2010, 2:575-582.

6. Yeilding N, Szapary P, Brodmerkel C, Benson J, Plotnick M, Zhou H, Goyal K, Schenkel B, Giles-Komar J, Mascelli MA, Guzzo C: Development of the IL-12/23 antagonist ustekinumab in psoriasis: past, present, and future perspectives. Ann N Y Acad Sci 2011, 1222:30-39.

7. Genovese MC, Van den Bosch F, Roberson SA, Bojin S, Biagini IM, Ryan P, Sloan-Lancaster J: LY2439821, a humanized anti-interleukin-17 monoclonal antibody, in the treatment of patients with rheumatoid arthritis: A phase I randomized, double-blind, placebo-controlled, proof-of-concept study. Arthritis Rheum 2010, 62:929-939.

8. Papp KA, Leonardi C, Menter A, Ortonne JP, Krueger JG, Kricorian G, Aras G, $\mathrm{Li}$ J, Russell CB, Thompson EH, Baumgartner S: Brodalumab, an antiinterleukin-17-receptor antibody for psoriasis. N Eng/ J Med 2012, 366:1181-1189.

9. Leonardi C, Matheson R, Zachariae C, Cameron G, Li L, Edson-Heredia E, Braun $D$, Banerjee S: Anti-interleukin-17 monoclonal antibody ixekizumab in chronic plaque psoriasis. N Eng/ J Med 2012, 366:1190-1199.

10. Cua DJ, Tato CM: Innate IL-17-producing cells: the sentinels of the immune system. Nat Rev Immunol 2010, 10:479-489.

11. Khader SA, Gaffen SL, Kolls JK: Th17 cells at the crossroads of innate and adaptive immunity against infectious diseases at the mucosa. Mucosal Immunol 2009, 2:403-411.

12. Yang YL, Leaw SN, Wang AH, Chen HT, Cheng WT, Lo HJ: Characterization of yeasts colonizing in healthy individuals. Med Mycol 2011, 49:103-106.

13. Jorda-Marcos R, Alvarez-Lerma F, Jurado M, Palomar M, Nolla-Salas J, Leon MA, Leon C: Risk factors for candidaemia in critically ill patients: a prospective surveillance study. Mycoses 2007, 50:302-310.

14. Antachopoulos C, Walsh TJ, Roilides E: Fungal infections in primary immunodeficiencies. Eur J Pediatr 2007, 166:1099-1117.

15. Kullberg BJ, Oude Lashof AM: Epidemiology of opportunistic invasive mycoses. Eur J Med Res 2002, 7:183-191.

16. Ho AW, Shen F, Conti HR, Patel N, Childs EE, Peterson AC, Hernández-Santos N, Kolls JK, Kane LP, Ouyang W, Gaffen SL: IL-17RC is required for immune signaling via an extended SEF/L-17R signaling domain in the cytoplasmic tail. J Immunol 2010, 185:1063-1070

17. Conti HR, Shen F, Nayyar N, Stocum E, Sun JN, Lindemann MJ, Ho AW, Hai JH, Yu JJ, Jung JW, Filler SG, Masso-Welch P, Edgerton M, Gaffen SL: Th17 cells and IL-17 receptor signaling are essential for mucosal host defense against oral candidiasis. J Exp Med 2009, 206:299-311. 
18. Huang W, Na L, Fidel PL, Schwarzenberger P: Requirement of interleukin17A for systemic anti-Candida albicans host defense in mice. J Infect Dis 2004, 190:624-631.

19. Kagami S, Rizzo HL, Kurtz SE, Miller LS, Blauvelt A: IL-23 and IL-17A, but not IL-12 and IL-22, are required for optimal skin host defense against Candida albicans. J Immunol 2010, 185:5453-5462.

20. Acosta-Rodriguez EV, Rivino L, Geginat J, Jarrossay D, Gattorno M, Lanzavecchia A, Sallusto F, Napolitani G: Surface phenotype and antigenic specificity of human interleukin 17-producing T helper memory cells. Nat Immunol 2007, 8:639-646.

21. Puel A, Picard C, Cypowyj S, Lilic D, Abel L, Casanova JL: Inborn errors of mucocutaneous immunity to Candida albicans in humans: a role for IL-17 cytokines? Curr Opin Immunol 2010, 22:467-474.

22. Marazzi MG, Bondi E, Giannattasio A, Strozzi M, Savioli C: Intracranial aneurysm associated with chronic mucocutaneous candidiasis. Eur $J$ Pediatr 2008, 167:461-463.

23. Loeys BL, Van Coster RN, Defreyne LR, Leroy JG: Fungal intracranial aneurysm in a child with familial chronic mucocutaneous candidiasis. Eur $\rfloor$ Pediatr 1999, 158:650-652.

24. Rautemaa R, Hietanen J, Niissalo S, Pirinen S, Perheentupa J: Oral and oesophageal squamous cell carcinoma - a complication or component of autoimmune polyendocrinopathy-candidiasis-ectodermal dystrophy (APECED, APS-I). Oral Oncol 2007, 43:607-613.

25. Eyerich K, Eyerich S, Hiller J, Behrendt H, Traidl-Hoffmann C: Chronic mucocutaneous candidiasis, from bench to bedside. Eur J Dermatol 2010, 20:260-265.

26. Kirkpatrick CH: Chronic mucocutaneous candidiasis. Pediatr Infect Dis J 2001, 20:197-206

27. Kisand K, Lilic D, Casanova JL, Peterson P, Meager A, Willcox N: Mucocutaneous candidiasis and autoimmunity against cytokines in APECED and thymoma patients: clinical and pathogenetic implications. Eur J Immunol 2011, 41:1517-1527.

28. Hanna S, Etzioni A: New host defense mechanisms against Candida species clarify the basis of clinical phenotypes. J Allergy Clin Immunol 2011, 127:1433-1437.

29. Ahonen P, Myllarniemi S, Sipila I, Perheentupa J: Clinical variation of autoimmune polyendocrinopathy-candidiasis-ectodermal dystrophy (APECED) in a series of 68 patients. N Engl J Med 1990, 322:1829-1836.

30. Kisand K, Bøe Wolff AS, Podkrajsek KT, Tserel L, Link M, Kisand KV, Ersvaer E, Perheentupa J, Erichsen MM, Bratanic N, Meloni A, Cetani F, Perniola R, Ergun-Longmire B, Maclaren N, Krohn KJ, Pura M, Schalke B, Ströbel P, Leite MI, Battelino T, Husebye ES, Peterson P, Willcox N, Meager A: Chronic mucocutaneous candidiasis in APECED or thymoma patients correlates with autoimmunity to Th17-associated cytokines. J Exp Med 2010, 207:299-308.

31. Puel A, Döffinger R, Natividad A, Chrabieh M, Barcenas-Morales G, Picard C, Cobat A, Ouachée-Chardin M, Toulon A, Bustamante J, Al-Muhsen S, AlOwain M, Arkwright PD, Costigan C, McConnell V, Cant AJ, Abinun M, Polak $M$, Bougnères PF, Kumararatne D, Marodi L, Nahum A, Roifman C, Blanche S, Fischer A, Bodemer C, Abel L, Lilic D, Casanova JL: Autoantibodies against IL-17A, IL-17F, and IL-22 in patients with chronic mucocutaneous candidiasis and autoimmune polyendocrine syndrome type I. J Exp Med 2010, 207:291-297.

32. Puel A, Cypowyj S, Bustamante J, Wright JF, Liu L, Lim HK, Migaud M, Israel L, Chrabieh M, Audry M, Gumbleton M, Toulon A, Bodemer C, El-Baghdadi J, Whitters M, Paradis T, Brooks J, Collins M, Wolfman NM, Al-Muhsen S, Galicchio M, Abel L, Picard C, Casanova JL: Chronic mucocutaneous candidiasis in humans with inborn errors of interleukin-17 immunity. Science 2011, 332:65-68.

33. Eyerich K, Foerster S, Rombold S, Seidl HP, Behrendt H, Hofmann H, Ring J, Traidl-Hoffmann C: Patients with chronic mucocutaneous candidiasis exhibit reduced production of Th17-associated cytokines IL-17 and IL-22. J Invest Dermatol 2008, 128:2640-2645.

34. Zelante T, lannitti R, De Luca A, Romani L: IL-22 in antifungal immunity. Eur J Immunol 2011, 41:270-275.

35. Aujla SJ, Chan YR, Zheng M, Fei M, Askew DJ, Pociask DA, Reinhart TA, McAllister F, Edeal J, Gaus K, Husain S, Kreindler JL, Dubin PJ, Pilewski JM, Myerburg MM, Mason CA, Iwakura Y, Kolls JK: IL-22 mediates mucosal host defense against Gram-negative bacterial pneumonia. Nat Med 2008, 14:275-281.

36. Saijo S, Ikeda S, Yamabe K, Kakuta S, Ishigame H, Akitsu A, Fujikado N, Kusaka
T, Kubo S, Chung SH, Komatsu R, Miura N, Adachi Y, Ohno N, Shibuya K, Yamamoto N, Kawakami K, Yamasaki S, Saito T, Akira S, Iwakura Y: Dectin-2 recognition of alpha-mannans and induction of Th17 cell differentiation is essential for host defense against Candida albicans. Immunity 2010, 32:681-691.

37. Chang SH, Dong C: A novel heterodimeric cytokine consisting of IL-17 and IL-17F regulates inflammatory responses. Cell Res 2007, 17:435-440.

38. Minegishi Y, Saito M, Tsuchiya S, Tsuge I, Takada H, Hara T, Kawamura N, Ariga T, Pasic S, Stojkovic O, Metin A, Karasuyama H: Dominant-negative mutations in the DNA-binding domain of STAT3 cause hyper-lgE syndrome. Nature 2007, 448:1058-1062.

39. Renner ED, Rylaarsdam S, Anover-Sombke S, Rack AL, Reichenbach J, Carey JC, Zhu Q, Jansson AF, Barboza J, Schimke LF, Leppert MF, Getz MM, Seger RA, Hill HR, Belohradsky BH, Torgerson TR, Ochs HD: Novel signal transducer and activator of transcription 3 (STAT3) mutations, reduced $\mathrm{T}(\mathrm{H}) 17$ cell numbers, and variably defective STAT3 phosphorylation in hyper-lgE syndrome. J Allergy Clin Immunol 2008, 122:181-187.

40. de Beaucoudrey L, Puel A, Filipe-Santos O, Cobat A, Ghandil P, Chrabieh M, Feinberg J, von Bernuth $H$, Samarina A, Jannière L, Fieschi C, Stéphan JL, Boileau C, Lyonnet S, Jondeau G, Cormier-Daire V, Le Merrer M, Hoarau C, Lebranchu Y, Lortholary O, Chandesris MO, Tron F, Gambineri E, Bianchi L, Rodriguez-Gallego C, Zitnik SE, Vasconcelos J, Guedes M, Vitor AB, Marodi L, et al:: Mutations in STAT3 and IL12RB1 impair the development of human IL-17-producing T cells. J Exp Med 2008, 205:1543-1550.

41. Milner JD, Brenchley JM, Laurence A, Freeman AF, Hill BJ, Elias KM, Kanno Y, Spalding C, Elloumi HZ, Paulson ML, Davis J, Hsu A, Asher Al, O'Shea J, Holland SM, Paul WE, Douek DC: Impaired T(H) 17 cell differentiation in subjects with autosomal dominant hyper-lgE syndrome. Nature 2008, 452:773-776.

42. Ma CS, Chew GY, Simpson N, Priyadarshi A, Wong M, Grimbacher B, Fulcher DA, Tangye SG, Cook MC: Deficiency of Th17 cells in hyper lgE syndrome due to mutations in STAT3. J Exp Med 2008, 205:1551-1557.

43. Minegishi Y, Saito M, Nagasawa M, Takada H, Hara T, Tsuchiya S, Agematsu K, Yamada M, Kawamura N, Ariga T, Tsuge I, Karasuyama H: Molecular explanation for the contradiction between systemic Th17 defect and localized bacterial infection in hyper-IgE syndrome. J Exp Med 2009, 206:1291-1301.

44. Conti HR, Baker O, Freeman AF, Jang WS, Holland SM, Li RA, Edgerton M, Gaffen SL: New mechanism of oral immunity to mucosal candidiasis in hyper-IgE syndrome. Mucosal Immunol 2011, 4:448-455.

45. Engelhardt KR, McGhee S, Winkler S, Sassi A, Woellner C, Lopez-Herrera G, Chen A, Kim HS, Lloret MG, Schulze I, EhI S, Thiel J, Pfeifer D, Veelken H, Niehues T, Siepermann K, Weinspach S, Reisli I, Keles S, Genel F, Kutukculer N, Camcioğlu Y, Somer A, Karakoc-Aydiner E, Barlan I, Gennery A, Metin A, Degerliyurt A, Pietrogrande MC, Yeganeh $M$, et al: Large deletions and point mutations involving the dedicator of cytokinesis 8 (DOCK8) in the autosomal-recessive form of hyper-IgE syndrome. J Allergy Clin Immunol 2009, 124:1289-1302.e4.

46. Zhang Q, Davis JC, Lamborn IT, Freeman AF, Jing H, Favreau AJ, Matthews HF, Davis J, Turner ML, Uzel G, Holland SM, Su HC: Combined immunodeficiency associated with DOCK8 mutations. N Engl J Med 2009, 361:2046-2055.

47. Su HC: Dedicator of cytokinesis 8 (DOCK8) deficiency. Curr Opin Allergy Clin Immunol 2010, 10:515-520.

48. Minegishi Y, Saito M, Morio T, Watanabe K, Agematsu K, Tsuchiya S, Takada H, Hara T, Kawamura N, Ariga T, Kaneko H, Kondo N, Tsuge I, Yachie A, Sakiyama Y, Iwata T, Bessho F, Ohishi T, Joh K, Imai K, Kogawa K, Shinohara M, Fujieda M, Wakiguchi H, Pasic S, Abinun M, Ochs HD, Renner ED, Jansson A, Belohradsky $\mathrm{BH}$, et al: Human tyrosine kinase 2 deficiency reveals its requisite roles in multiple cytokine signals involved in innate and acquired immunity. Immunity 2006, 25:745-755

49. Grant AV, Boisson-Dupuis S, Herquelot E, de Beaucoudrey L, Filipe-Santos O, Nolan DK, Feinberg J, Boland A, Al-Muhsen S, Sanal O, Camcioglu Y, Palanduz A, Kilic SS, Bustamante J, Casanova JL, Abel L: Accounting for genetic heterogeneity in homozygosity mapping: application to Mendelian susceptibility to mycobacterial disease. J Med Genet 2011, 48:567-571.

50. Liu L, Okada S, Kong XF, Kreins AY, Cypowyj S, Abhyankar A, Toubiana J, Itan Y, Audry M, Nitschke P, Masson C, Toth B, Flatot J, Migaud M, Chrabieh M, Kochetkov T, Bolze A, Borghesi A, Toulon A, Hiller J, Eyerich S, Eyerich K, Gulácsy V, Chernyshova L, Chernyshov V, Bondarenko A, Grimaldo RM, Blancas-Galicia L, Beas IM, Roesler J, et al:: Gain-of-function human STAT1 mutations impair IL-17 immunity and underlie chronic mucocutaneous candidiasis. J Exp Med 2011, 208:1635-1648. 
51. van de Veerdonk FL, Plantinga TS, Hoischen A, Smeekens SP, Joosten LA, Gilissen C, Arts P, Rosentul DC, Carmichael AJ, Smits-van der Graaf CA, Kullberg BJ, van der Meer JW, Lilic D, Veltman JA, Netea MG: STAT1 mutations in autosomal dominant chronic mucocutaneous candidiasis. NEngl J Med 2011, 365:54-61.

52. Filipe-Santos O, Bustamante J, Chapgier A, Vogt G, de Beaucoudrey L, Feinberg J, Jouanguy E, Boisson-Dupuis S, Fieschi C, Picard C, Casanova J: Inborn errors of IL-12/23- and IFN-gamma-mediated immunity: molecular, cellular, and clinical features. Semin Immuno/ 2006, 18:347-361.

53. de Beaucoudrey L, Samarina A, Bustamante J, Cobat A, Boisson-Dupuis S, Feinberg J, Al-Muhsen S, Jannière L, Rose Y, de Suremain M, Kong XF, FilipeSantos O, Chapgier A, Picard C, Fischer A, Dogu F, Ikinciogullari A, Tanir G, Al-Hajjar S, Al-Jumaah S, Frayha HH, AlSum Z, Al-Ajaji S, Alangari A, AlGhonaium A, Adimi P, Mansouri D, Ben-Mustapha I, Yancoski J, Garty BZ, et al.: Revisiting human IL-12Rbeta1 deficiency: a survey of 141 patients from 30 countries. Medicine (Baltimore) 2010, 89:381-402.

54. Ghilardi N, Ouyang W: Targeting the development and effector functions of TH17 cells. Semin Immunol 2007, 19:383-393.

55. Drummond RA, Saijo S, Iwakura Y, Brown GD: The role of Syk/CARD9 coupled C-type lectins in antifungal immunity. Eur J Immunol 2011, 41:276-281

56. Drummond RA, Brown GD: The role of Dectin- 1 in the host defence against fungal infections. Curr Opin Microbio/ 2011, 14:392-399.

57. Ferwerda B, Ferwerda G, Plantinga TS, Willment JA, van Spriel AB, Venselaar $H$, Elbers CC, Johnson MD, Cambi A, Huysamen C, Jacobs L, Jansen T, Verheijen K, Masthoff L, Morré SA, Vriend G, Williams DL, Perfect JR, Joosten LA, Wijmenga C, van der Meer JW, Adema GJ, Kullberg BJ, Brown GD, Netea MG: Human dectin-1 deficiency and mucocutaneous fungal infections. N Engl J Med 2009, 361:1760-1767.

58. Plantinga TS, van der Velden WJ, Ferwerda B, van Spriel AB, Adema G, Feuth T, Donnelly JP, Brown GD, Kullberg BJ, Blijlevens NM, Netea MG: Early stop polymorphism in human DECTIN-1 is associated with increased candida colonization in hematopoietic stem cell transplant recipients. Clin Infect Dis 2009, 49:724-732

59. Gross O, Gewies A, Finger K, Schafer M, Sparwasser T, Peschel C, Forster I, Ruland J: Card9 controls a non-TLR signalling pathway for innate antifungal immunity. Nature 2006, 442:651-656.

60. Strasser D, Neumann K, Bergmann H, Marakalala MJ, Guler R, Rojowska A, Hopfner KP, Brombacher F, Urlaub H, Baier G, Brown GD, Leitges M, Ruland J: Syk kinase-coupled C-type lectin receptors engage protein kinase C-delta to elicit Card9 adaptor-mediated innate immunity. Immunity 2012, 36:32-42.

61. LeibundGut-Landmann S, Gross O, Robinson MJ, Osorio F, Slack EC, Tsoni SV, Schweighoffer E, Tybulewicz V, Brown GD, Ruland J, Reis e Sousa C: Syk- and CARD9-dependent coupling of innate immunity to the induction of T helper cells that produce interleukin 17. Nat Immuno/ 2007, 8:630-638.

62. Dennehy KM, Ferwerda G, Faro-Trindade I, Pyz E, Willment JA, Taylor PR, Kerrigan A, Tsoni SV, Gordon S, Meyer-Wentrup F, Adema GJ, Kullberg BJ, Schweighoffer E, Tybulewicz V, Mora-Montes HM, Gow NA, Williams DL, Netea $M G$, Brown GD: Syk kinase is required for collaborative cytokine production induced through Dectin-1 and Toll-like receptors. Eur J Immunol 2008, 38:500-506.

63. Glocker EO, Hennigs A, Nabavi M, Schäffer AA, Woellner C, Salzer U, Pfeifer D, Veelken H, Warnatz K, Tahami F, Jamal S, Manguiat A, Rezaei N, Amirzargar AA, Plebani A, Hannesschläger N, Gross O, Ruland J, Grimbacher B: A homozygous CARD9 mutation in a family with susceptibility to fungal infections. N Engl J Med 2009, 361:1727-1735.

64. Gaffen SL: Structure and signalling in the IL-17 receptor family. Nat Rev Immunol 2009, 9:556-567.

65. Picard C, Casanova JL, Puel A: Infectious diseases in patients with IRAK-4 MyD88, NEMO, or IkappaBalpha deficiency. Clin Microbiol Rev 2011, 24:490-497.
66. Klatt NR, Brenchley JM: Th17 cell dynamics in HIV infection. Curr Opin HIV AIDS 2010, 5:135-140.

67. Rossie K, Guggenheimer J: Oral candidiasis: clinical manifestations, diagnosis, and treatment. Pract Periodontics Aesthet Dent 1997, 9:635-641; quiz 642.

68. Shoham S, Han G, Granek T, Walsh T, Magee MF: Association between blood glucose levels and development of candidemia in hospitalized patients. Endocr Pract 2009, 15:111-115.

69. Mclnnes IB, Schett G: The pathogenesis of rheumatoid arthritis. N Engl J Med 2011, 365:2205-2219.

70. Furst DE: The risk of infections with biologic therapies for rheumatoid arthritis. Semin Arthritis Rheum 2010, 39:327-346.

71. Salliot C, Dougados M, Gossec L: Risk of serious infections during rituximab, abatacept and anakinra treatments for rheumatoid arthritis: metaanalyses of randomised placebo-controlled trials. Ann Rheum Dis 2009, 68:25-32.

72. Tsiodras S, Samonis G, Boumpas DT, Kontoyiannis DP: Fungal infections complicating tumor necrosis factor alpha blockade therapy. Mayo Clin Proc 2008, 83:181-194

73. Filler SG, Yeaman MR, Sheppard DC: Tumor necrosis factor inhibition and invasive fungal infections. Clin Infect Dis 2005, 41 Suppl 3:S208-212.

74. Cohen S, Hurd E, Cush J, Schiff M, Weinblatt ME, Moreland LW, Kremer J, Bear MB, Rich WJ, McCabe D: Treatment of rheumatoid arthritis with anakinra, a recombinant human interleukin-1 receptor antagonist, in combination with methotrexate: results of a twenty-four-week, multicenter, randomized, double-blind, placebo-controlled trial. Arthritis Rheum 2002, 46:614-624.

75. Krueger GG, Langley RG, Leonardi C, Yeilding N, Guzzo C, Wang Y, Dooley LT, Lebwohl M: A human interleukin-12/23 monoclonal antibody for the treatment of psoriasis. N Engl J Med 2007, 356:580-592.

76. Gordon KB, Papp KA, Langley RG, Ho V, Kimball AB, Guzzo C, Yeilding N, Szapary PO, Fakharzadeh S, Li S, Hsu MC, Reich K: Long-term safety experience of ustekinumab in patients with moderate to severe psoriasis (Part II of II): Results from analyses of infections and malignancy from pooled phase II and III clinical trials. J Am Acad Dermatol 2012, 66:742-751.

77. Reich K, Langley RG, Papp KA, Ortonne JP, Unnebrink K, Kaul M, Valdes JM: A 52-week trial comparing briakinumab with methotrexate in patients with psoriasis. N Engl J Med 2011, 365:1586-1596.

78. Gordon KB, Langley RG, Gottlieb AB, Papp KA, Krueger GG, Strober BE, Williams DA, Gu Y, Valdes JM: A phase III, randomized, controlled trial of the fully human IL-12/23 mAb briakinumab in moderate-to-severe psoriasis. J Invest Dermatol 2012, 132:304-314.

79. Weinblatt ME, Kavanaugh A, Genovese MC, Musser TK, Grossbard EB, Magilavy DB: An oral spleen tyrosine kinase (Syk) inhibitor for rheumatoid arthritis. NEngl J Med 2010, 363:1303-1312.

80. Kremer JM, Cohen S, Wilkinson BE, Connell CA, French JL, Gomez-Reino J, Gruben D, Kanik KS, Krishnaswami S, Pascual-Ramos V, Wallenstein G, Zwillich $\mathrm{SH}$ : A phase $2 \mathrm{~B}$ dose-ranging study of the oral JAK inhibitor tofacitinib (CP-690,550) versus placebo in combination with background methotrexate in patients with active rheumatoid arthritis and inadequate response to methotrexate alone. Arthritis Rheum 2012, 64:970-981.

doi:10.1186/ar3893

Cite this article as: Huppler AR, et al:: Mucocutaneous candidiasis: the IL-17 pathway and implications for targeted immunotherapy. Arthritis Research \& Therapy 2012, 14:217. 